\title{
Cement Mortar Reinforced with Palm Nuts Naturals Fibers: Study of the Mechanical Properties
}

\author{
Christian Bopda Fokam ${ }^{1 *}$, Eric Toumi ${ }^{1}$, Bienvenu Kenmeugne $^{1}$, Lucien Meva'a ${ }^{1}$, Khalifa Mansouri $^{2}$ \\ ${ }^{1}$ Laboratoire Engineering Civil et Mécanique de l'Ecole Nationale Supérieure Polytechnique (ENSP) de l'Université de \\ Yaoundé 1, Cameroon \\ ${ }^{2}$ Laboratoire SSDIA, Ecole Normale Supérieure de l'Enseignement Technique, Univ. Hassan II Mohammedia Casablanca, Bd \\ Hassan II, Mohammedia, Morocco
}

Corresponding Author Email: christian.fokam@polytechnique.cm

https://doi.org/10.18280/rcma.300102

Received: 18 September 2019

Accepted: 7 December 2019

\section{Keywords:}

natural fiber, palm nut, cement mortar, mechanical property, sustainability

\begin{abstract}
This paper presents an experimental study of the influence of the addition of palm nut fiber on the mechanical strength of cement mortar. Cement mortar specimens reinforced with naturals palm nut fibers have been developed containing between 0 and $3.5 \%$ volume fraction fibers. Compression test and flexural test (3-point bending test) are performed on the different samples. It is found from the flexural test that the flexural strength of the mortar reinforced with palm nuts increases slightly regardless of the maturation time of the sample. Conversely, compression tests show a gradual decrease in mechanical strength with the addition of fibers.
\end{abstract}

\section{INTRODUCTION}

Fiber-reinforced cement mortar is used in the field of construction, in the context of renovation as well as in the construction of new buildings [1-4]. The specificity of its formulation makes it a mortar with interesting mechanical properties in terms of durability. Fiber mortar consists of siliceous sands, cements, synthetic fibers.

The drop in oil reserves and increased awareness of the pollution caused by the use of synthetic fibers $[5,6]$ has sparked an interest in natural fibers, renewable and biodegradable resources. For economic reasons, the studies carried out on these fibers mainly concern industrially produced plants (for example, banana, cotton, palm kernel, flax, hemp, etc.) in the world [7-9].

Today, the development of natural fiber-reinforced composites is one of the most attractive research areas. Çomak et al. [10] studied the influence of hemp fibers on the properties of cement-based mortar. During the studies, they made hemp fiber incorporated with cement mortar of different quantities $(0 \%, 1 \%, 2 \%$ and $3 \%)$ and different lengths $(6 \mathrm{~mm}$, $12 \mathrm{~mm}$ and $18 \mathrm{~mm}$ ). From the analysis, they concluded that cement mortars reinforced with $2-3 \%$ of fiber and $12 \mathrm{~mm}$ length of natural hemp fiber gave the best results. Danso et al. [11] investigated the effect of coconut fibers and lime on the characteristics of soil-cement mortar, they concluded that coconut fibers and lime positively influence soil-cement mortar properties for construction application with the optimum strength recorded at $0.2 \%$ fiber and $5 \%$ lime addition of the specimen.

Kesikidou et al. [12] studied mortars reinforced with natural fibers. The study gives more clarity on the use of bio-fibers in construction materials to enhance the recycling of bio-fibers in the domain of construction. Three types of natural fiber (jute, coconut and kelp) were applied as additives in $1.5 \%$ by mortar volume.

The importance of fibers in lime mortars and cement mortars were evaluated using mechanical, physical and microstructural characteristics of the specimens. The results showed that natural fibers increased the strength and life span of the composite.

Ramakrishna et al. [13] conducted studies on the impact resistance of slabs constructed from natural fiber-reinforced cement mortar. These authors demonstrated that the addition of natural coconut fibers between $0.5 \%$ and $2.5 \%$ greatly improved the impact resistance of the slab. Vantadori et al. [14] worked instead on mortars reinforced with date palm fibers. They showed that an increase in fiber content improved the ductility/weight ratio of the cement mortar.

The natural fibers used in this study are palm nut fibers from the western region of Cameroon. They were extracted from oil palms of the E-Elaeis guineensis variety by a combination of processes comprising various steps: mechanical and washing, drying [15].

In Cameroon, oil palm accounts for a significant part of agricultural activity. It is cultivated for the oil contained in the nuts. Most often waste such as palm nut fibers and husks are discarded in the wild or disposed of by burning in situ. This study aims to valorize its waste from oil palm cultivation and to offer farmers new economic prospects. The construction sector must play an important role in solving the environmental problems linked to recycling and the exploitation of biomass. In the field of construction, in Africa, natural fiber-reinforced earth mortars are still widely used in the construction industry (cob, adobe, adobe, etc.). Nevertheless, cement matrix mortars remain the reference building material in cities. In this article we are interested in the potential use of palm nut fibers as reinforcing elements for 
cement mortars (as a partial substitute for sand) to make cinder blocks.

The objective of this research is to study the influence of the addition of palm nut fibers on the mechanical properties of cement mortar. First of all, we developed fiber-reinforced cement mortar specimens respecting the choice of constituent elements according to the required standards. More precisely, we are interested in the consequences that the incorporation of the fibers into the cement material generates. The flexural and compression tests will be performed.

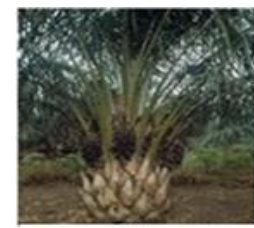

(a)

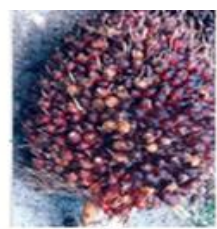

(b)

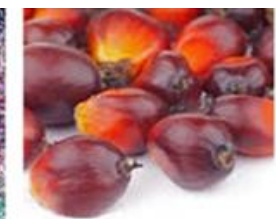

(c)

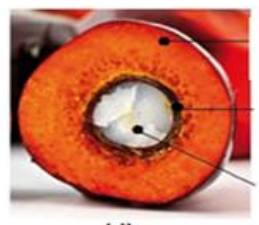

(d)

Figure 1. Presentation of an oil palm and its diet: (a) the oil palm, (b) the diet, (c) the whole palm nut (d) Cut of the palm nut

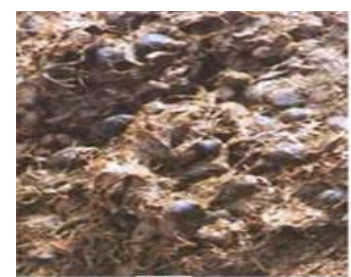

(a)

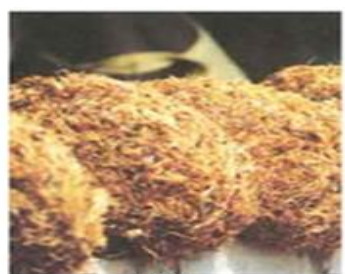

(b)

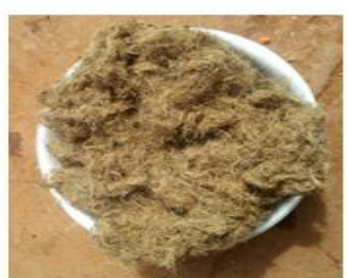

(c)

Figure 2. Fiber states after extraction from the mechanical oil press: (a) Waste from the press (b) Raw fibers (c) Entangled fibers cleaned (by washing with water)

The fibers are extracted from the palm nut pulp using a mechanical oil press. The raw fibers, thus obtained are washed with water at a temperature of $70^{\circ} \mathrm{C}$. Figure 2 shows the state of the fibers during the different extraction steps. The mechanical extraction has the advantage of roughening the outer surface of the fibers and thus contributes to the improvement of matrix-stiffness adhesion [16, 17].

The average dimensions of extracting fibers are presented in Table 1.

Table 1. Average size of extracted fibers

\begin{tabular}{cc}
\hline Designation & Value \\
\hline Fiber lengths & $24 \mathrm{~mm}-49 \mathrm{~mm}$ \\
$\begin{array}{c}\text { Radius of the large diameter } \\
\text { section of the fiber }\end{array}$ & $0.46 \mathrm{~mm}-0.87 \mathrm{~mm}$ \\
$\begin{array}{c}\text { Radius of the small diameter } \\
\text { section of the fiber }\end{array}$ & $0.16 \mathrm{~mm}-0.37 \mathrm{~mm}$ \\
\hline
\end{tabular}

\subsection{Manufacture of fiber-reinforced cement mortar sample}

Extracted palm nut fibers are used in the manufacture of cement mortar specimens. A cement mortar reinforced with short natural fibers is obtained. The fiber-reinforced cement mortar specimens consist of:

- Sand: The sand used comes from the Yong River, Mbalmayo town (Central Region, Cameroon) because it lacks clay and impurities. We used $0 / 2$ sand in accordance with the standard NF EN 196-1 (Sand 0-2 mm).

- Cement: The cement used is of type CEMI BP 42.5R compliant with the standard NC 234: 2009-06 and manufactured in Cameroon by the DANGOTE CEMENT factory in Cameroon.

- Fiber: fiber extracted from the palm nut pulp of the western region of Cameroon (Density of the fiber: $521 \mathrm{~kg} \mathrm{~m}^{-}$ $3)$.

- The mixing water used is free of impurities and complies with NF P 18-303 (Water/cement ratio=0.6)

The fiber-reinforced cement mortar specimens are prismatic in size $40 \mathrm{~mm} \times 40 \mathrm{~mm} \times 160 \mathrm{~mm}$, for a volume of $256.10-6 \mathrm{~m}^{3}$ (see Figure 3 ) for the flexural test. For the compression test, the dimensions used are $40 \mathrm{~mm} \times 40 \mathrm{~mm} \times 80 \mathrm{~mm}$. These dimensions are in accordance with the European standard NF EN 196-1 describing the procedure for determining the mechanical resistance of cement materials. Table 2 shows the compositions of the various cement mortar specimens (Indication of the fiber quantity of the different mortar specimens)

For each test specimen designation, mechanical tests will be performed taking into account the drying time of the mortar (or maturation time of the mortar) between 7 and 28 days.

Table 2. Fiber Composition of different cement mortar specimens

\begin{tabular}{cc}
\hline Reference & $\begin{array}{c}\text { Percentage of fibers (volume } \\
\text { fraction fibre) }\end{array}$ \\
\hline MF0 & $0 \%$ \\
MF0.5 & $0.5 \%$ \\
MF1 & $1 \%$ \\
MF2 & $2 \%$ \\
MF3 & $3 \%$ \\
MF3.5 & $3.5 \%$ \\
\hline
\end{tabular}




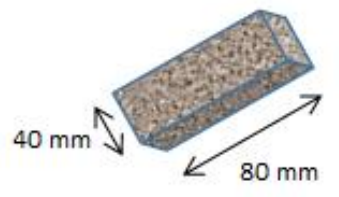

Compression test sample

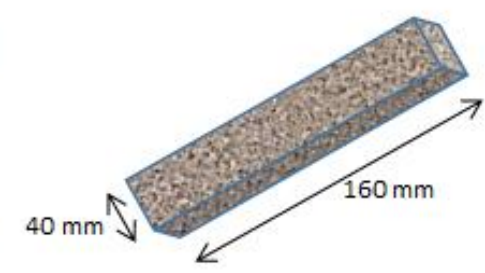

Flexural test sample
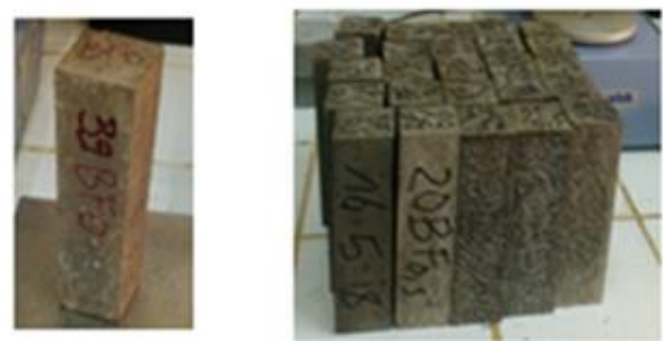

Figure 3. Fibered cement mortar sample

\subsection{Tensile/compression test machine}

The tensile / compression machine used for our tests is a CONTROLAB brand with numerical control and a data acquisition system (see Figure 4). The movement of the cross is ensured by a hydraulic cylinder. From a suitable assembly, this tensile/compression machine was used to perform the 3point bending tests on our fiber-reinforced mortar specimens (Figure 3).

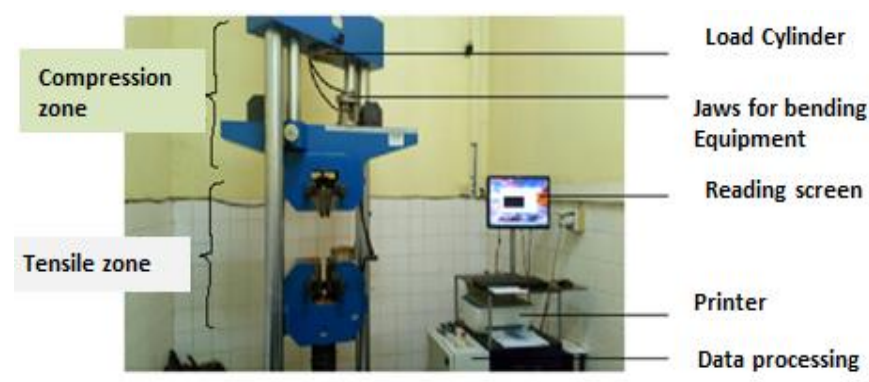

Figure 4. Tensile/compression testing machine
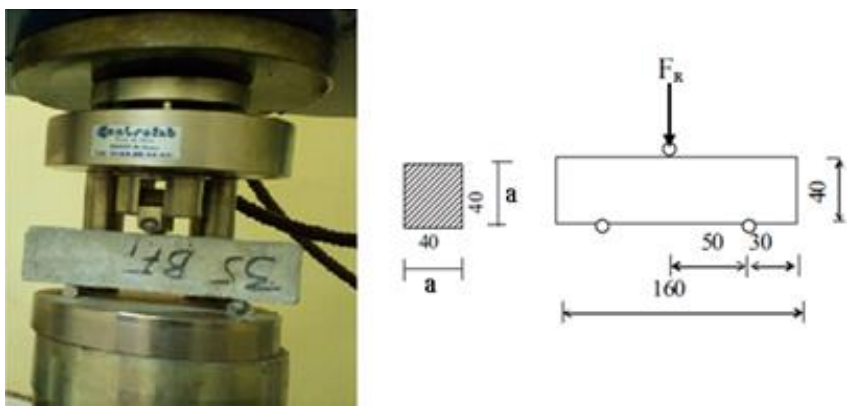

Figure 5. Tensile/compression testing machine

Figure 5 illustrates the sample mooring system for the 3point bend test.

\section{RESULTS AND DISCUSSIONS}

In this section of the study, we present our test results of the mechanical properties of specimens of fiber-reinforced cement mortar (gotten from the Three-point flexural test and compression test).

\subsection{Density of fiber cement mortar specimens}

In this section, we have determined density of cement mortar samples $\left(\rho=M_{105}{ }^{\circ} / V\right)$ at different fiber reinforcement levels.
With $\mathrm{M}_{105^{\circ} \mathrm{C}}$ : dry mass of the specimen obtained after passing through the oven at $105^{\circ} \mathrm{C}(\mathrm{Kg})$ and V: Sample volume $\left(\mathrm{m}^{3}\right)$.

In Figure 6 we find that the bulk density decreases progressively from a value of $2277.5 \mathrm{~kg} / \mathrm{m}^{3}$ for the $0 \%$ fiber sample to a value of 942.1 for the $3.5 \%$ fiber sample. At equal volume, the mortar containing palm kernel fiber is lighter than a control mortar without fiber cement.

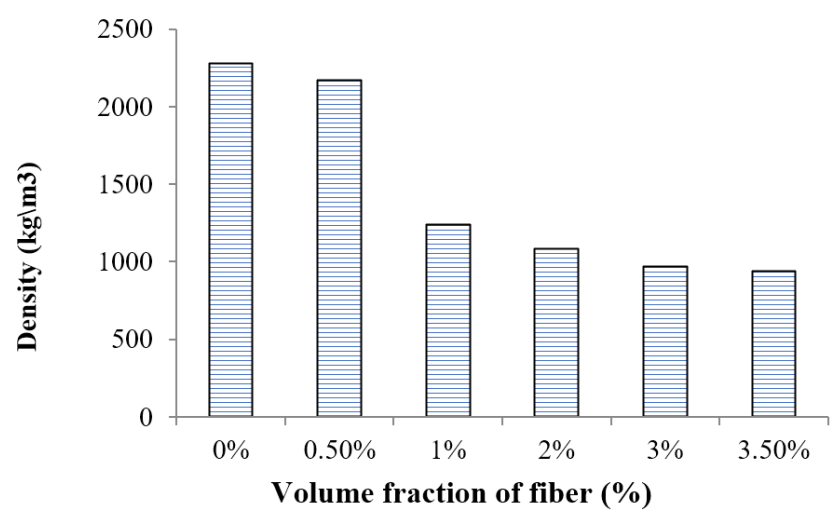

Figure 6. Evolution of density according de volume fraction of fiber

\subsection{Analysis of flexural tests on fiber mortar specimens}

The results presented in the figures below are obtained from the Three-point flexural tests until fracture of fiber cement mortar specimens. For each test on the different samples (distinguished by their fiber quantity and their drying time or maturation time of the mortar in days), the ultimate flexural strength is measured (corresponding at the maximal tensile stress of the structure).

Figure 7 below shows the evolution of the flexural strength as a function of the fiber content and for a drying time or maturation time of the mortar specimens between 7 to 28 days. The values obtained from the flexural test are plotted in Figure 7.

According to the graph in Figure $7 \mathrm{a}$, whatever the drying time, a gradual increase in the flexural strength has observed at first, then followed by a decrease. The maximum values of the flexural strength are obtained for a quantity of fibers of approximately $2 \%$ in the mortar sample of fiber mortar. Beyond a content of $2 \%$, there is a slight deterioration in the strengths of the reinforced mortar.

On the other hand, in Figure 7b, it is clearly seen that the maturation time of our fiber mortar samples makes it possible to increase the flexural strength. The addition of small quantity of fiber and increase maturation time improves the flexural strength of the cement mortar. 


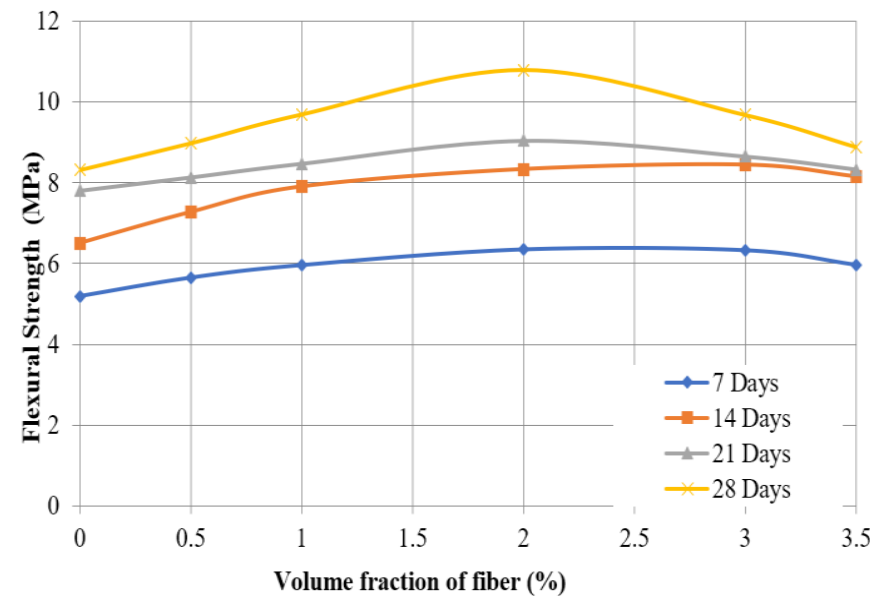

(a)

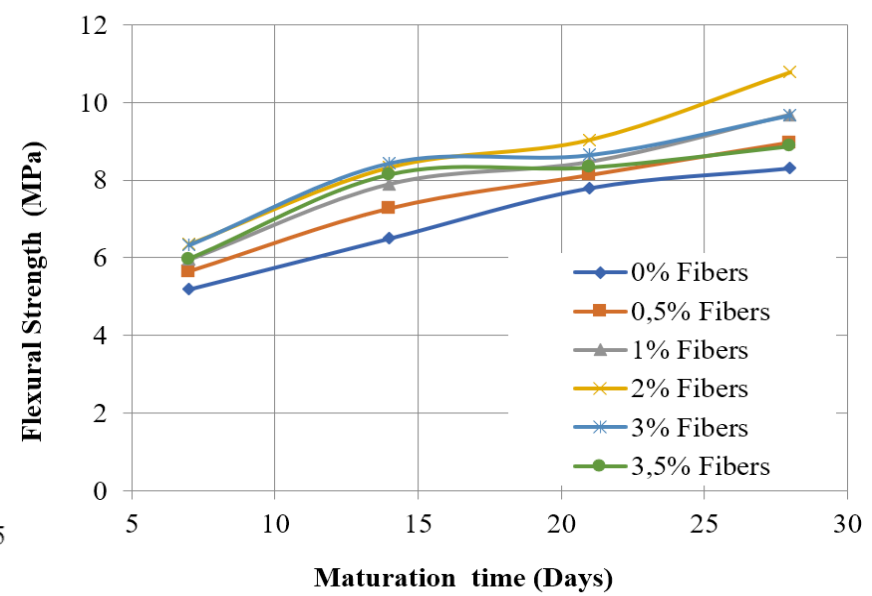

(b)

Figure 7. (a) Evolution of the flexural strength as a function of the quantity of fibers, (b) Evolution of the flexural strength as a function of the maturation time of mortar specimens (or drying time)

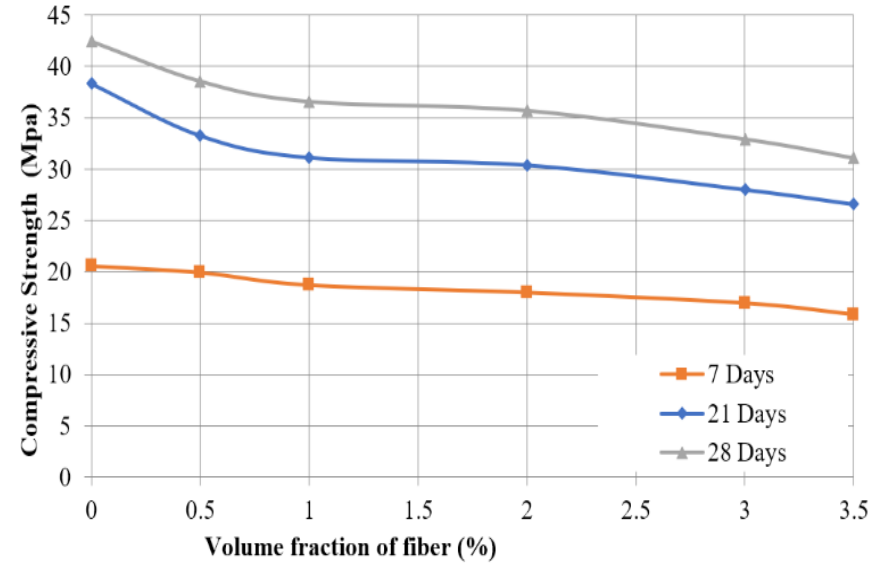

(a)

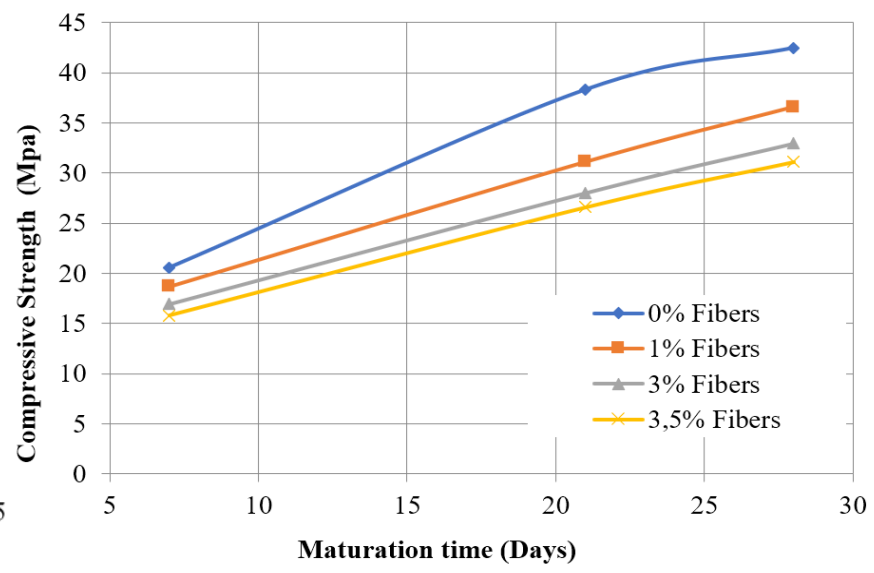

(b)

Figure 8. (a) Evolution of the compressive strength as a function of the quantity of fiber, (b) Evolution of the compressive strength as a function of the maturation time (or drying time)

\subsection{Analysis of compressive tests on fibered mortar}

The results presented in this section relate to the compression tests carried out on the different ranges of fiberreinforced cement mortar specimens. For each sample tested, the compressive strength and Young's modulus are recorded.

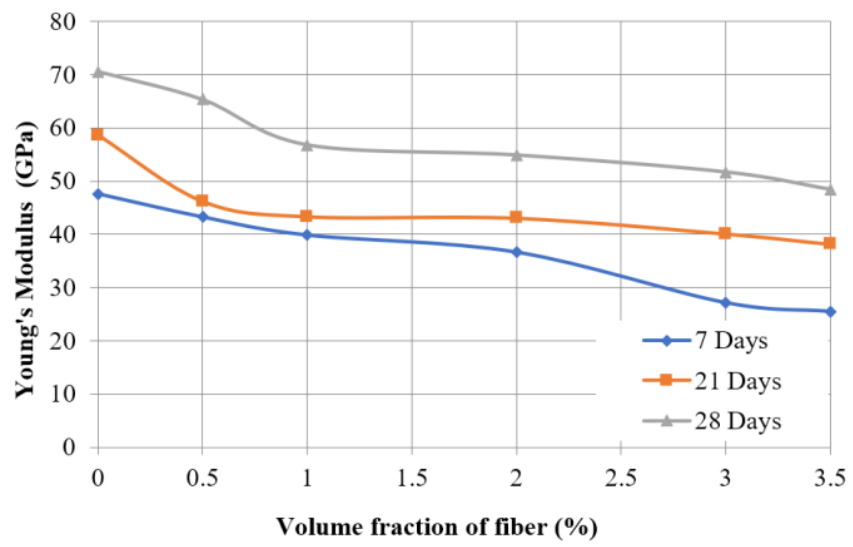

Figure 9. Evolution of Young's modulus as a function of the quantity of fiber
Figure 8 above shows the evolution of the compressive strength as a function of the quantity of fibers at different maturities times of 7 to 28 days.

In contrast to the Three-point flexural test, Figure 8a shows a gradual and steady decrease in the compressive strength in relation to the increase in the volume fraction of fibers. Figure $8 \mathrm{~b}$ shows clearly that the unreinforced specimens made of fiber (at $0 \%$ ) have a better compressive strength than fibered specimens, at 28 days it goes from a value of $42.4 \mathrm{MPa}$ (for $0 \%$ of fiber) at $31.1 \mathrm{MPa}$ (for $3.5 \%$ fiber).

There is a similar effect of the quantity of fiber on the other, mechanical characteristics in compression such as Young's modulus. In Figure 9, it can be seen that an increase in the quantity of fiber causes a progressive decrease in Young's modulus.

\section{CONCLUSIONS}

This article has presented an experimental study of the influence of the quantity of vegetable fibers of palm nuts on the mechanical properties of cement mortar. Cement mortar specimens reinforced with palm nut fibers of volume fractions between 0 and $3.5 \%$ of fibers were developed. The flexural tests clearly show an improvement in the flexural strength of 
the mortar with the addition of the fibers. This beneficial effect seems to decrease in quantity of fiber greater than $2 \%$. A controlling effect of the addition of fiber on the compressive strength is observed. Indeed, an increase in the quantity of fiber causes a progressive loss of compressive strength.

\section{REFERENCES}

[1] Lau, K.T., Hung, P.Y., Zhu, M.H., Hui, D. (2018). Properties of natural fibre composites for structural engineering applications. Compos B. Eng, 136: 222-233. http://dx.doi.org/10.1016/j.compositesb.2017.10.038

[2] Blankenhorn, P.R., Silsbee, M.R., Blankenhorn, B.D., Dicola, M. (1999). Temperature and moisture effect on selected properties of wood fiber-cement composites. Cement and Concrete Research, 29: 737. https://doi.org/10.1016/S0008-8846(99)00046-0

[3] Govin, A. (2004). Aspects physico-chimiques de l'interaction bois-ciment/Modification de l'hydratation du ciment par le bois. PhD Thesis -Saint-Etienne School of Mines-France.

[4] Yakum., R. (2014). Comparative study of commercial and palm oil empty fruit bunch fiber with preliminary study in the production of empty fruit bunch fiber cement board. PhD Thesis- Faculté des Sciences: Université de Douala-Cameroon.

[5] Groover, M.P. (2004). Fundamental of Modern Manufacturing. 4th eds, John Wiley \& Sons, United States of America.

[6] Malkapuram, R., Kumar, V., Yuvraj, S.N. (2008). Recent development in natural fibre reinforced polypropylene composites. J Reinf Plast Compos, 28: 1169-1189. https://doi.org/10.1177/0731684407087759

[7] Grégoire, M., Ouagne, P., Barthod-Malat, B., Evon, P., Labonne, L., Placet, V. (2019). Extraction of linseed flax fibres for technical textiles: Influence of pre-treatment parameters on the fibre yield, the mechanical properties and the mechanical properties. Revue des Composites et des Materiaux Avances, 29(5): 293-298. https://doi.org/10.18280/rcma.290503

[8] Amziane, S., Collet F., Lawrence M., Magnion C., Picandet V. (2017). Round robin test for hemp shiv characterisation: Part 1 Evaluation of initial water content and water absorption. Bio-Aggregates Based
Building Materials, v. 23, springer, The NetherlandsAmsterdam. https://doi.org/10.1007/978-94-024-1031-0

[9] Bono, P., Le Duc, A., Lozachmeur, M., Day, A. (2015). Les nouveaux champs de recherche et développement pour la valorisation des fibres végétales techniques (lin fibres et chanvre). Oilseeds et fats Crops and Lipids OCL, 22(6): 613. https://doi.org/10.1051/ocl/2015041

[10] Çomak, B., Bideci, A., Bideci, O.S. (2018). Effects of hemp fibers on characteristics of cement based mortar. Construction and Building Materials, 169: 794-799. https://doi.org/10.1016/j.conbuildmat.2018.03.029

[11] Danso, H., Manu, D. (2019). Influence of coconut fibres and lime on the properties of soil-cement mortar. Case Studies in Construction Materials, 12: e00316. https://doi.org/10.1016/j.cscm.2019.e00316

[12] Kesikidou, F., Stefanidou, M. (2019). Natural fiberreinforced mortars. Journal of Building Engineering, 25: 100786. https://doi.org/10.1016/j.jobe.2019.100786

[13] Ramakrishna, G., Sundararajan, T. (2005). Impact strength of a few natural fibre reinforced cement mortar slabs: A comparative study. Cement \& Concrete Composites, 27(5): 547-553. https://doi.org/10.1016/j.cemconcomp.2004.09.006

[14] Vantadori, S., Carpinteri, A., Zanichelli, A. (2019). Lightweight construction materials: Mortar reinforced with date-palm mesh fibres. Theoretical and Applied Fracture Mechanics, 100: 39-45. https://doi.org/10.1016/j.tafmec.2018.12.011

[15] Venkateshwaran, N., ElayaPerumal, A. (2012). Mechanical and water absorption properties of woven jute/banana hybrid composites. Fibers and Polymers, 13: 907-914. http://dx.doi.org/10.1007/s12221-012-0907-0

[16] Baley, C., Busnel, F., Grohens, Y., Sire, O. (2006). Influence of chemical treatments on surface properties and adhesion of flax fibre-polyester resin. Composite Part A: Applied Science and Manufacturing, 37(10): 1626-1637. https://doi.org/10.1016/j.compositesa.2005.10.014

[17] Le Duigou, A., Bourmaud, A., Davies, P., Baley, C. (2011). Etude des mécanismes d'adhérence entre une fibre de lin et le PLLA- Influence d'un traitement faiblement impactant à l'eau. 17èmes Journées Nationales sur les Composites (JNC17), PoitiersFuturoscope, France. p. 89. 